\title{
BMJ Open Anticipated responses to a hypothetical minimum price for cigarettes and roll- your-own tobacco: an online cross- sectional survey with cigarette smokers and ex-smokers in the UK
}

\author{
Nathan Critchlow (D) , Crawford Moodie, Catherine Best (D) , Martine Stead
}

To cite: Critchlow N, Moodie C, Best C, et al. Anticipated responses to a hypothetical minimum price for cigarettes and roll-your-own tobacco: an online cross-sectional survey with cigarette smokers and exsmokers in the UK. BMJ Open 2021;11:e042724. doi:10.1136/ bmjopen-2020-042724

- Prepublication history for this paper is available online. To view these files, please visit the journal online (http://dx.doi. org/10.1136/bmjopen-2020042724).

Received 14 July 2020 Revised 30 December 2020 Accepted 05 March 2021

\section{Check for updates}

(c) Author(s) (or their employer(s)) 2021. Re-use permitted under CC BY-NC. No commercial re-use. See rights and permissions. Published by BMJ.

Institute for Social Marketing and Health, University of Stirling, Stirling, UK

Correspondence to

Dr Nathan Critchlow;

nathan.critchlow@stir.ac.uk

\section{ABSTRACT}

Objectives As tobacco companies can circumvent tax increases, a minimum retail price per-cigarette/pergram of roll-your-own tobacco presents an additional mechanism for governments to reduce smoking. We examined (1) anticipated responses to a hypothetical minimum price-per-cigarette/per-gram among smokers in the UK; (2) what demographic and smoker characteristics are associated with anticipated responses; and (3) whether minimum pricing may help ex-smokers stay quit.

Design Cross-sectional survey (May-July 2019).

Setting UK.

Participants Adult cigarette smokers $(n=2412)$ and exsmokers $(n=700)$.

Main outcome measurements Anticipated responses to a hypothetical minimum price of $£ 10.00$ for 20 cigarettes (£0.50 per-cigarette) and $£ 13.50$ for 30 grams of rollyour-own tobacco (£0.45 per-gram); approximately $£ 0.10$ per-cigarette/per-gram increases on the cheapest prices in leading UK supermarkets (January 2019). Smokers were presented with ten options (eg, 'Try to quit') and asked which they would do (Yes/No) and then which they would most likely do. Ex-smokers were asked to what extent the minimum prices would help them stay quit (A lot vs Lesser agreement).

Results Among smokers, $55.6 \%$ said they would most likely smoke the same amount, $10.7 \%$ they would smoke less, $9.5 \%$ they would try to quit and $5.8 \%$ they would use e-cigarettes more often. Anticipated reactions were associated with demography and smoker characteristics, for example, C2DE (lower social grade) smokers were less likely than $A B C 1$ (higher social grade) smokers to say they would smoke the same as they do now $\left(\mathrm{OR}_{\mathrm{Adj}}=0.74\right.$, $95 \% \mathrm{Cl} 0.62$ to 0.88 ). Among ex-smokers, $38.5 \%$ said the minimum prices would help them stay quit 'A lot', more so among C2DE than $\mathrm{ABC} 1$ participants $\left(\mathrm{OR}_{\mathrm{Adj}}=1.80,95 \% \mathrm{Cl}\right.$ 1.30 to 2.49 ).

Conclusions In response to a hypothetical minimum price for cigarettes and roll-your-own tobacco, approximately a fifth of smokers in the UK indicated they would smoke less or quit and almost two-fifths of ex-smokers indicated the prices would help them stay quit.

\section{Strengths and limitations of this study}

- The study provides important consumer insight concerning how cigarette smokers and ex-smokers in the UK anticipate responding to a minimum retail price for cigarettes and roll-your-own tobacco.

- The study examines the anticipated impact of a minimum retail price on variety of outcomes among consumers in the UK, including smoking (eg, 'smoke less than I do now'), purchasing source (eg, 'buy illicit cigarettes or tobacco') and likelihood of exsmokers staying quit.

- The large sample supports robust statistical analyses to examine the relationships between demography, smoking behaviour and anticipated reactions among UK consumers.

- The study only examines anticipated consumer reactions to one set of hypothetical minimum retail prices for cigarettes and roll-your-own tobacco in the UK, and the data do not control for the confounding influence of existing price paid for tobacco or granular measurements of disposable income and deprivation.

- The data are cross-sectional and cannot demonstrate causal associations between demography, smoking behaviour and anticipated reactions to the minimum retail prices among consumers in the UK.

\section{INTRODUCTION}

Price is an important determinant of smoking. ${ }^{1-4}$ While low prices enable more consumers to use tobacco, particularly pricesensitive groups such as young people and those of lower socioeconomic status, ${ }^{56}$ high prices present a barrier. Reducing affordability, by increasing price, is therefore a cost-effective means of reducing uptake and increasing cessation. ${ }^{7-10}$

Prices for cigarettes and roll-your-own tobacco are typically controlled through taxation. In the UK, taxation for cigarettes comprises a duty per-1000 cigarettes and an 
ad valorem duty $(16.5 \%$ of recommended retail price (RRP) ). ${ }^{11}$ Taxation for roll-your-own tobacco is a single duty per-kilogram. ${ }^{11}$ Duty rates for cigarettes and rollyour-own are subject to frequent escalation above inflation rates ${ }^{1213}$ and sales are subject to $20 \%$ Value-Aadded Tax (VAT) ${ }^{12}$ On 20 May 2017, the UK also introduced a Minimum Excise Tax (MET) for cigarettes, under which the duty became either the standard duty rates or a minimum duty per-1000 cigarettes, whichever was higher in monetary value. ${ }^{14}$ This created a de facto floor price, as selling below this threshold meant that duty would exceed sales revenue. The MET is also subject to escalation above inflation, with the MET in November $2020 £ 320.90$ per-1000 cigarettes; equating to approximately $£ 6.41$ per-20 cigarettes ( $£ 7.70$ including VAT; or approximately $£ 0.39$ per-cigarette). ${ }^{11}$ In the UK, the price of cigarettes and roll-your-own has also been indirectly influenced by the Tobacco and Related Products Regulations 2016 which, from 20 May 2017, mandated minimum pack sizes of 20 for cigarettes and 30 grams (g) for roll-your-own. ${ }^{15}$ Before this, multiple smaller pack sizes were available, many of which sold in high volumes. ${ }^{16}{ }^{17}$ Although these minimum sizes do not directly influence price-per-cigarette or per-gram, they do influence the overall retail price of a pack to the consumer.

Higher prices and reduced affordability are associated with greater motivation to stop smoking and many smokers identify a price-point at which they would seriously consider quitting. ${ }^{18-21}$ However, tobacco companies can shift tax increases across brand portfolios to preserve affordability for price-sensitive consumers; for instance, charging extra for more expensive variants (overshifting) and absorbing tax increases for the least expensive variants (undershifting). ${ }^{22-26}$ Consequently, there is growing interest in non-taxation mechanisms for price control, including a minimum mark-up on wholesale price, a price cap to limit overshifting duty increases onto premium products and a minimum retail price (hereafter 'minimum pricing'). ${ }^{27}$ Sales modelling data suggest that minimum pricing may reduce smoking prevalence, and the effects may be greater than achieved through taxation alone. ${ }^{27} 28$ As tobacco prices are reportedly lower in the most income-deprived areas, ${ }^{29}$ minimum pricing may also have a greater relative impact on more economically disadvantaged smokers, thus helping reduce health inequalities. ${ }^{28-30}$

Key to understanding the impact of minimum pricing is exploring how smokers anticipate reacting (eg, attempting to quit) and unintended consequences (eg, purchasing illicit tobacco), factors not readily accounted for in modelling studies. ${ }^{28}$ We examine (1) anticipated responses to a hypothetical minimum priceper-cigarette/per-gram among smokers in the UK; (2) what demographic and smoker characteristics are associated with anticipated outcomes; and (3) whether minimum pricing may help ex-smokers in the UK to stay quit.

\section{METHODS}

\section{Design and sample}

Data come from the Adult Tobacco Policy Survey (ATPS). A cohort of cigarette smokers in the UK were recruited April/May $2016(\mathrm{n}=6233)$ and followed up September/ November $2017(\mathrm{n}=4293)$ and May/July $2019(\mathrm{n}=3175)$. This cross-sectional analysis is based on the wave three sample only. The survey was conducted by YouGov, who recruited the sample from their non-probabilistic online panel. All participants who completed wave one were contacted for wave three. Participants received approximately 400 points on their YouGov account (equivalent to $£ 4.00$ ) for participation at wave three. A cross-sectional weight was provided for the third wave, based on age, gender, region and tobacco consumption, to represent the national profile of smokers aged $\geq 16$ years in the UK, based on the Opinions and Lifestyle Survey and Integrated Household Survey (weight Median=0.73; $\mathrm{IQR}=0.57-0.95$ ).

\section{Measures}

Demographics

Data were collected on age (coded: 19-34, 35-54, 55-64, $\geq 65$ years), gender, country (coded: England vs Other) and social grade, with participants classified ABC1 (middle and upper classes, hereafter 'higher social grade') or C2DE (working classes, hereafter 'lower social grade') using the National Readership Survey system. ${ }^{31}$

\section{Cigarette smoking status}

All participants were cigarette smokers at wave one. To assess smoking behaviour at wave three, participants were asked 'Which of the following best describes your CURRENT smoking status?': (1) I smoke cigarettes (including handrolled) every day; (2) I smoke cigarettes (including handrolled), but not every day; (3) I do not smoke cigarettes at all, but I do smoke tobacco of some kind (eg, pipe, cigar or shisha); (4) I have stopped smoking completely in the past year; (5) I stopped smoking completely more than a year ago; or (6) Don't know. Those selecting 'I smoke cigarettes every day' were categorised as 'cigarette smokers'. Those who answered 'I smoke cigarettes, but not every day' were subsequently asked 'Can we just confirm, how often do you currently smoke cigarettes (either factory-made or handrolled)' and could indicate: (1) At least once a week; (2) Less than once a week, but at least once a month; (3) Less than once a month, but at least once in the last 3 months; (4) I have not smoked cigarettes in the last 3 months; or (5) Don't Know. Those answering 1-3 were also categorised as 'cigarette smokers' and the remainder excluded. Those who indicated that they had stopped smoking completely in the past year, or more than a year ago, were categorised as 'ex-smokers'.

\section{Heaviness of Smoking Index}

To estimate nicotine dependence, cigarette smokers completed the Heaviness of Smoking Index (HSI). ${ }^{32} 33$ They were asked the number of cigarettes (including hand-rolled) they typically smoked per-day, 
per-week or per-month; the latter two were converted into daily estimates. The daily estimates were coded as: (0) $\leq 10$ cigarettes; (1) 11-20 cigarettes; (2) 21-30 cigarettes; or (3) $\geq 31$ cigarettes. Participants also reported time until first cigarette on days they smoked, with answers: (0) more than 1 hour; (1) 31-60 min; (2) 6-30 min; (3) within $5 \mathrm{~min}$; or 'Don't Know'. Results for both items were summed (range 0-6) and participants coded as light $(0-1)$, moderate $(2-3)$ or heavy smokers $(4-6) \cdot{ }^{34-37}$ Those not providing valid answers for time to first cigarette were coded 'Not stated' for HSI category.

\section{Cessation intentions}

Cigarette smokers were asked 'Are you planning to quit smoking?' with response options: (1) 'Within the next month'; (2) 'Between one and 6 months from now'; (3) 'Sometime in the future, beyond 6 months'; (4) 'Not planning to quit'; or (5) 'Don't know'. Responses were coded into those who reported some intentions to quit (codes: 1-3), those who did not (code: 4) and 'Don't know'.

\section{Thoughts about the cost of smoking}

To measure price sensitivity, cigarette smokers were asked 'In the last 30 days how often, if at all, have you thought about how much money you spend on smoking'. Responses were provided on a five-point scale ( $1=$ Never to $5=$ Very often; Don't know), which was converted into Very often/Often (codes $4 / 5$, hereafter 'Often') versus Less often/Never (codes: 1-3). 'Don't know' responses were excluded.

\section{Anticipated reactions to a hypothetical minimum price-per- cigarette or per-gram}

To establish a minimum price, we identified the cheapest pack of 20 cigarettes and $30 \mathrm{~g}$ of roll-your-own in UK supermarkets in the month the third survey wave was developed (January 2019). Data came from an audit which captures monthly information on tobacco products sold online by the four leading tobacco-selling supermarkets (Asda/Tesco/Sainsbury's/Morrisons). ${ }^{38} 39$ In January 2019, the cheapest packs of 20 cigarettes were $£ 8.00$ (Tesco/Sainsbury’s), $£ 8.30$ (Morrisons) and $£ 8.35$ (Asda), equivalent to approximately $£ 0.40-£ 0.42$ percigarette. We set the hypothetical minimum price at $£ 0.50$ per-cigarette, an approximate $£ 0.10$ increase on the lowest prices. In January 2019, the cheapest pack of $30 \mathrm{~g}$ roll-your-own was $£ 9.89$ in Asda, $£ 10.00$ in Sainsbury's, $£ 10.25$ in Tesco and £10.50 in Morrisons; equivalent to $£ 0.33-£ 0.35$ per-gram. We set the hypothetical minimum price at $£ 0.45$ per-gram, matching the approximate $£ 0.10$ increase applied to cigarettes. Between establishing the minimum prices and the fieldwork, there was no recorded increase in tax duty for cigarettes (overall/MET) or rollyour-own. ${ }^{11}$ Prices were checked again during the months that data were collected. In June 2019, across the four supermarkets, the cheapest 20 cigarettes were £0.42$£ 0.43$ per-cigarette (£8.30-£8.69 per 20 cigarettes) and the cheapest $30 \mathrm{~g}$ roll-your-own were approximately $£ 0.35$ per-gram (range £10.43-£10.50 per $30 \mathrm{~g}$ ), showing no substantial change from development and still below the hypothetical minimum prices of $£ 0.50$ per-cigarette and $£ 0.45$ per-gram.

Cigarette smokers were prompted with the statement 'If the cheapest pack of 20 cigarettes available for sale in the UK was £10, and the cheapest pack of 30 grams of rolling tobacco was $£ 13.50$...' and presented with eight responses concerning smoking behaviour (eg, 'Smoke less than I do now'), purchasing behaviour (eg, 'Use a cheaper tobacco product some of the time or all of the time') and purchasing source (eg, 'Buy illicit cigarettes or tobacco'). These reflect outcomes reported in existing price sensitivity research. ${ }^{20}$ The question was presented twice. On first presentation, the prompt statement was suffixed with '...which, if any, of following do you think you would do?' and participants were invited to select all that applied. On second presentation, the prompt statement was suffixed with '...which, if any, of the following do you think you would be MOST likely to do?' and participants could select only one. For each question, participants could also indicate 'Don't know' or 'Other'.

Ex-smokers were prompted with the same statement, but this time suffixed with '...to what extent, if at all, do you think the price of cigarettes/rolling tobacco would help you stay quit?' Responses were provided on a four-point scale ( $1=$ Not at all to $4=A$ lot; Don't know), which was converted into 'A lot' (code: 4) versus a lesser extent (codes 1-3). 'Don't know' responses were excluded.

\section{Ethics}

The third wave of the ATPS was approved by the University of Stirling's General University Ethics Panel (GUEP652). Participants provided informed consent to participate.

\section{Patient and public involvement}

No specific public and patient involvement activities were conducted. The measures and study design were informed by the two preceding waves of the ATPS.

\section{Analysis}

Data were analysed using SPSS V.23. Overall, 3175 participants responded to wave three $(50.9 \%$ retention to wave one). The wave three sample comprised 2412 cigarette smokers and 700 ex-smokers. The remainder reported only using other forms of tobacco (eg, cigars) $(n=44)$, had not smoked in the past 3 months $(n=6)$ or said 'Don't know' for smoking status $(n=13)$, and were excluded from analyses.

Among cigarette smokers, weighted frequencies are reported for demographics, frequency of thinking about the cost of smoking, what they thought they would do in response to the hypothetical minimum prices (all reactions) and what they would most likely do. Among cigarette smokers, binary logistic regressions examined to what extent demographics or smoking characteristics were associated with thinking about the cost of smoking in the past month (Often vs Less often/Never) and which outcome they would most likely do in response to the 
minimum prices (each: Yes/No). In each regression, the covariates were age, gender, country, social grade, HSI category, cessation intentions, and frequency of thinking about the cost of smoking (anticipated reaction models only). For the increased use of e-cigarettes reaction, the model additionally controlled for existing e-cigarette use (codes ranging: Never user to Daily). Regressions were unweighted as the variables used to construct the weights were included as covariates. Reference categories and the contrast functions are reported in the Results.

Among ex-smokers, weighted frequencies are reported for demographics and the proportion who said that the minimum prices would help them stay quit (A lot vs Lower agreement). An unweighted binary logistic regression examined to what extent demographics were associated with reporting that the minimum prices would help them to stay quit ( $A$ lot vs Lower agreement). Covariates included age, gender, country, social grade, and recency of quitting (In the past year vs More than a year ago). Reference categories and the contrast functions are reported in the Results.

Table 1 Sample characteristics of current cigarette smokers and ex-smokers in wave three of the Adult Tobacco Policy Survey (ATPS)

\begin{tabular}{|c|c|c|c|c|c|c|c|c|}
\hline \multirow[b]{3}{*}{ Variable } & \multicolumn{4}{|c|}{ Cigarette smokers } & \multicolumn{4}{|c|}{ Ex-cigarette smokers } \\
\hline & \multicolumn{2}{|c|}{ Unweighted } & \multicolumn{2}{|c|}{ Weighted } & \multicolumn{2}{|c|}{ Unweighted } & \multicolumn{2}{|c|}{ Weighted } \\
\hline & $\%$ & $\mathbf{n}$ & $\%$ & $\mathbf{n}$ & $\%$ & $\mathbf{n}$ & $\%$ & $\mathbf{n}$ \\
\hline \multicolumn{9}{|l|}{ Age } \\
\hline 19-34 years & 13.1 & 317 & 37.0 & 880 & 17.9 & 125 & 43.7 & 317 \\
\hline $35-54$ years & 43.7 & 1054 & 37.5 & 890 & 43.0 & 301 & 34.7 & 252 \\
\hline $55-64$ years & 22.3 & 537 & 14.0 & 332 & 18.4 & 129 & 11.1 & 81 \\
\hline$\geq 65$ years & 20.9 & 504 & 11.5 & 273 & 20.7 & 145 & 10.5 & 76 \\
\hline \multicolumn{9}{|l|}{ Gender } \\
\hline Male & 47.8 & 1153 & 53.1 & 1262 & 47.4 & 332 & 47.2 & 343 \\
\hline Female & 52.2 & 1259 & 46.9 & 1113 & 52.6 & 368 & 52.8 & 384 \\
\hline \multicolumn{9}{|l|}{ Country } \\
\hline England & 82.3 & 1984 & 82.4 & 1957 & 83.3 & 583 & 84.0 & 610 \\
\hline Other & 17.7 & 428 & 17.6 & 419 & 16.7 & 117 & 16.0 & 116 \\
\hline \multicolumn{9}{|l|}{ Social grade } \\
\hline ABC1 (higher) & 57.2 & 1363 & 62.2 & 1464 & 60.1 & 412 & 60.9 & 435 \\
\hline C2DE (lower) & 42.8 & 1019 & 37.8 & 889 & 39.9 & 273 & 39.1 & 279 \\
\hline Missing/Not stated & - & 30 & - & 23 & - & 15 & - & 13 \\
\hline \multicolumn{9}{|l|}{ Heaviness of smoking ${ }^{*} \dagger$} \\
\hline Light & 38.1 & 903 & 47.2 & 1100 & - & - & - & - \\
\hline Moderate & 43.8 & 1036 & 37.7 & 879 & - & - & - & - \\
\hline Heavy & 18.1 & 429 & 15.0 & 351 & - & - & - & - \\
\hline Missing/Not stated & - & 44 & - & 46 & - & - & - & - \\
\hline \multicolumn{9}{|l|}{ Intentions to quit* } \\
\hline No intention & 31.3 & 754 & 32.6 & 774 & - & - & - & - \\
\hline Some intention & 53.5 & 1291 & 54.2 & 1288 & - & - & - & - \\
\hline Do not know & 15.2 & 367 & 13.2 & 313 & - & - & - & - \\
\hline \multicolumn{9}{|l|}{ Recency of cessation } \\
\hline In the past year & - & - & - & - & 46.9 & 328 & 50.5 & 367 \\
\hline More than a year ago & - & - & - & - & 53.1 & 372 & 49.5 & 360 \\
\hline
\end{tabular}

*Only asked of current cigarette smokers.

†Measured using the Heaviness of Smoking Index (HSI), which accounts for cigarettes typically smoked per day and time to first cigarette in the morning.

‡Only asked of ex-cigarette smokers. Participants were minimum 16 years when recruited at wave one, so minimum age in wave three was 19 years. 


\section{RESULTS}

\section{Sample characteristics}

Cigarette smokers and ex-smokers ranged from 19 to 34 to $>65$ years old, with a similar proportion of males and females. Most participants were from England (vs Scotland, Wales or Northern Ireland), and more were from the higher social grades (ABC1) than the lower grades (C2DE) (table 1). Around two-fifths of cigarette smokers were either light or moderate smokers and approximately half of cigarette smokers reported some quit intentions. Around half of ex-smokers reported quitting in the year prior and the other half more than a year ago.

\section{Thinking about the cost of smoking}

A fifth of cigarette smokers (20.5\%, weighted) thought 'Often' about how much money they had spent on smoking, less so among males than females (Adjusted OR
$\left(\mathrm{OR}_{\mathrm{Adj}}\right)=0.74,95 \%$ CI 0.60 to $\left.0.92, \mathrm{p}=0.006\right)$ (table 2$)$. There was also an association with HSI, after adjusting for demography, with moderate $\left(\mathrm{OR}_{\mathrm{Adj}}=1.88,95 \% \mathrm{CI} 1.47\right.$ to $2.41, \mathrm{p}<0.001)$ and heavy smokers $\left(\mathrm{OR}_{\mathrm{Adj}}=2.84,95 \%\right.$ CI 2.10 to $3.84, \mathrm{p}<0.001$ ) more likely to think about the cost 'Often' versus light smokers. Smokers with some quit intentions $\left(\mathrm{OR}_{\mathrm{Adj}}=5.02,95 \% \mathrm{CI} 3.73\right.$ to $\left.6.77, \mathrm{p}<0.001\right)$, or who were unsure on their quit intentions $\left(\mathrm{OR}_{\mathrm{Adj}}=2.61\right.$, $95 \%$ CI 1.78 to $3.83, \mathrm{p}<0.001$ ), were also more likely to think about the cost 'Often' versus those with no quit intentions.

\section{Anticipated reactions to the hypothetical minimum prices among cigarette smokers}

When first asked about possible responses to the hypothetical minimum prices, where multiple options could be selected, more than half of cigarette smokers said they

Table 2 Logistic regression exploring the association between demographics, smoking characteristics and thinking about the cost of smoking often among cigarette smokers

\begin{tabular}{|c|c|c|c|c|}
\hline \multirow[b]{2}{*}{ Variable and reference categories } & \multirow[b]{2}{*}{$\mathbf{n}$} & \multicolumn{3}{|c|}{ Thinking about the cost of smoking often } \\
\hline & & $\mathbf{O R}_{\mathrm{Adj}}$ & $95 \% \mathrm{Cl}$ & $\begin{array}{l}P \\
\text { value }\end{array}$ \\
\hline Age & & & & 0.160 \\
\hline 19-34 years & 304 & REF & - & - \\
\hline $35-54$ years (vs younger) & 1016 & 0.93 & 0.66 to 1.30 & 0.667 \\
\hline $55-64$ years (vs younger) & 520 & 0.87 & 0.65 to 1.16 & 0.342 \\
\hline$>65$ years (vs younger) & 489 & 1.29 & 1.00 to 1.68 & 0.054 \\
\hline \multicolumn{5}{|l|}{ Gender } \\
\hline Female & 1218 & REF & - & - \\
\hline Male & 1111 & 0.74 & 0.60 to 0.92 & 0.006 \\
\hline \multicolumn{5}{|l|}{ Country } \\
\hline England & 1925 & REF & - & - \\
\hline Other & 404 & 1.13 & 0.86 to 1.48 & 0.373 \\
\hline \multicolumn{5}{|l|}{ Social grade } \\
\hline ABC1 (higher) & 1335 & REF & - & - \\
\hline C2DE (lower) & 994 & 1.21 & 0.97 to 1.49 & 0.086 \\
\hline Heaviness of smoking & & & & $<0.001$ \\
\hline Light & 886 & REF & - & - \\
\hline Moderate (vs light) & 1019 & 1.88 & 1.47 to 2.41 & $<0.001$ \\
\hline Heavy (vs light) & 424 & 2.84 & 2.10 to 3.84 & $<0.001$ \\
\hline Intentions to quit & & & & $<0.001$ \\
\hline No intention & 729 & REF & - & - \\
\hline Some intention (vs no intention) & 1257 & 5.02 & 3.72 to 6.77 & $<0.001$ \\
\hline Not stated (vs no intention) & 343 & 2.61 & 1.78 to 3.83 & $<0.001$ \\
\hline
\end{tabular}

Unweighted base: Current cigarette smokers $(n=2412)$.

Dependent variable: Thinking about cost of smoking in the past 30 days (Very often/Often vs Less Often/Never).

Data are unweighted.

Data missing on one or more variables $(\mathrm{n}=83)$.

Hosmer and Lemeshow: $\chi^{2}(8)=3.29, p=0.915$.

$\chi^{2}$ test of coefficients for model: $\chi^{2}(10)=212.24, p<0.001$; Nagelkerke $R^{2}=0.135$.

Classification accuracy in final model stage: $78.7 \%$.

$\mathrm{OR}_{\text {Adj, }}$, adjusted odds ratio. 
would 'smoke the same amount as I do now' (58.8\%) (table 3). One-in-six stated they would 'smoke less than I do now' $(15.9 \%)$ or 'try to quit' $(14.5 \%)$, while less than one-in-ten indicated that they would 'use e-cigarettes some or all the time' $(9.7 \%)$, 'buy cheap cigarettes or tobacco online/abroad' (7.8\%) or 'buy illicit cigarettes or tobacco' $(6.8 \%)$.

When asked which outcome they would most likely do, where only one option could be selected, more than half of cigarette smokers reported they would 'smoke the same amount as I do now' (55.6\%) (table 3). Around one-in-ten indicated that they would 'smoke less than I do now' $(10.7 \%)$ or 'try to quit' $(9.5 \%)$. A smaller proportion said they would 'use e-cigarettes some or all of time' $(5.8 \%)$, 'buy cheaper cigarettes or tobacco online/ abroad' $(5.0 \%)$, 'buy illicit cigarettes or tobacco' $(2.8 \%)$ or 'use a cheaper tobacco product some or all of the time' $(1.7 \%)$. Only a small number suggested they would 'smoke more than I do now' (1.3\%).

\section{Associations between demography, smoking characteristics and anticipated reactions}

Logistic regressions identified associations between most likely reactions to the minimum prices and demography (tables 4 and 5). Age was associated with reporting 'smoke the same amount as I do now' ( $\mathrm{p}=0.019)$, with those aged 55-64 years less likely to endorse this versus younger age groups $\left(\mathrm{OR}_{\mathrm{Adj}}=0.74,95 \%\right.$ CI 0.59 to 0.93 , $\mathrm{p}=0.009$ ). There was also an association between age and endorsing 'try to quit' $(\mathrm{p}<0.001)$, with those aged 55-64 years $\left(\mathrm{OR}_{\mathrm{Adj}}=1.85,95 \%\right.$ CI 1.28 to $\left.2.67, \mathrm{p}=0.001\right)$ or $\geq 65$ years $\left(\mathrm{OR}_{\mathrm{Adj}}=1.57,95 \%\right.$ CI 1.11 to $\left.2.21, \mathrm{p}=0.010\right)$ more likely to endorse this than younger age groups. Men were more likely to endorse 'purchase illicit cigarettes or tobacco' than women $\left(\mathrm{OR}_{\mathrm{Adj}}=1.76,95 \%\right.$ CI 1.06 to 2.95, $\mathrm{p}=0.031)$. Lower social grade cigarette smokers (C2DE) were less likely than those in the higher social grades (ABC1) to indicate that they would 'smoke the same amount as I do now' $\left(\mathrm{OR}_{\mathrm{Adj}}=0.74,95 \%\right.$ CI 0.62 to 0.88 , $\mathrm{p}<0.001$ ), but more likely to endorse 'buy illicit cigarettes or tobacco' $\left(\mathrm{OR}_{\mathrm{Adj}}=3.03,95 \%\right.$ CI 1.73 to $\left.5.32, \mathrm{p}<0.001\right)$ or 'use a cheaper tobacco product some or all of the time' $\left(\mathrm{OR}_{\mathrm{Adj}}=2.18,95 \%\right.$ CI 1.06 to $\left.4.50, \mathrm{p}=0.035\right)$.

After controlling for demography, the logistic regressions showed associations between most likely anticipated reactions to the minimum prices and HSI category (tables 4 and 5). Specifically, heavy smokers were less likely to endorse 'smoke less than I do now' $\left(\mathrm{OR}_{\mathrm{Adj}}=0.43\right.$, $95 \%$ CI 0.27 to $0.68, \mathrm{p}<0.001)$ versus light smokers. Conversely, moderate $\left(O R_{A d j}=2.37,95 \%\right.$ CI 1.14 to 4.93 , $\mathrm{p}=0.021)$ and heavy smokers $\left(O R_{A d j}=4.10,95 \%\right.$ CI 1.91 to $8.83, \mathrm{p}<0.001$ ) were more likely to endorse 'buy illicit cigarettes or tobacco' than light smokers. Moderate smokers $\left(O R_{A d j}=2.93,95 \%\right.$ CI 1.14 to $\left.7.56, \mathrm{p}=0.026\right)$ and heavy smokers $\left(O R_{A d j}=3.02,95 \%\right.$ CI 1.02 to $\left.8.99, \mathrm{p}=0.047\right)$ were also more likely to endorse 'use a cheaper tobacco product some or all of the time' than light smokers.

Table 3 Anticipated reactions to the hypothesised minimum prices for cigarettes and roll-your-own tobacco among cigarette smokers in the UK

\section{If the cheapest pack of $\mathbf{2 0}$ cigarettes available for sale in the UK was $£ 10.00$, and the cheapest pack of $30 \mathrm{~g}$ of rolling tobacco was $£ 13.50 .$.}

\begin{tabular}{|c|c|c|c|c|}
\hline \multirow[b]{2}{*}{ Reaction to hypothesised minimum pricing } & \multicolumn{2}{|c|}{$\begin{array}{l}\text {...which, if any, of the following do } \\
\text { you think you would do?* }\end{array}$} & \multicolumn{2}{|c|}{$\begin{array}{l}\text {...which, if any, of the following } \\
\text { do you think you would be } \\
\text { MOST likely to do?† }\end{array}$} \\
\hline & $\%$ & $\mathbf{n}$ & $\%$ & $\mathbf{n}$ \\
\hline Smoke the same amount as I do now & 58.8 & 1397 & 55.6 & 1321 \\
\hline Smoke less than I do now & 15.9 & 379 & 10.7 & 254 \\
\hline Try to quit & 14.5 & 344 & 9.5 & 227 \\
\hline Buy cheaper cigarettes or tobacco online or abroad & 7.8 & 185 & 5.0 & 120 \\
\hline Don'tt know & 7.4 & 177 & 6.8 & 162 \\
\hline Buy illicit cigarettes or tobacco & 6.8 & 162 & 2.8 & 66 \\
\hline $\begin{array}{l}\text { Use a cheaper tobacco product some or all of the } \\
\text { time }\end{array}$ & 4.4 & 104 & 1.7 & 40 \\
\hline
\end{tabular}

Base=All current cigarette smokers.

Data are weighted.

*Participants could select all that applied; \% do not sum to 100; it was not possible for participants to select contrasting answers (eg, both 'smoke the same as I do now' and 'smoke less than I do now').

†Participants could only select one option, \% do sum to 100. 


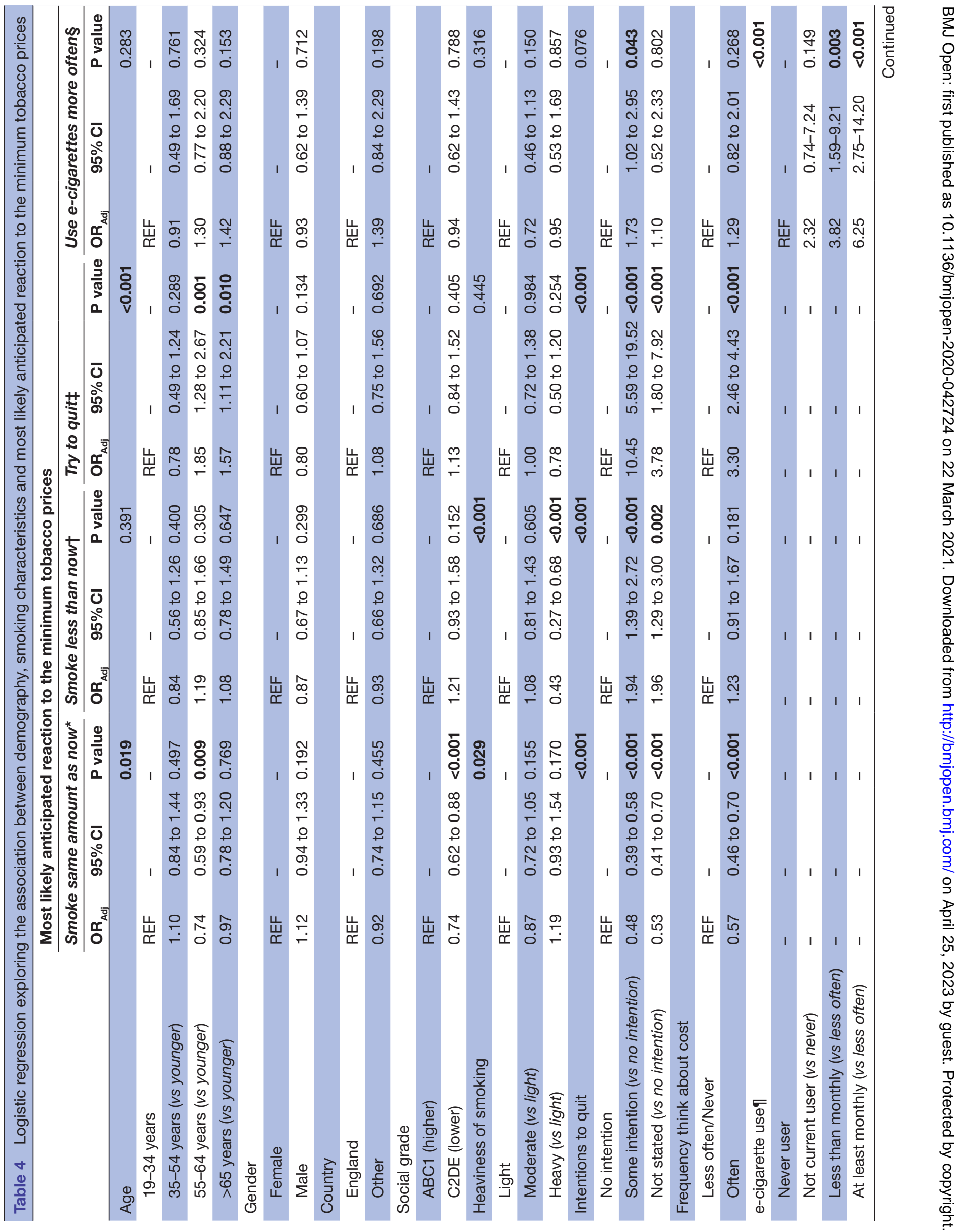




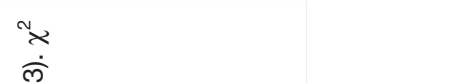

After controlling for demography, the logistic regressions also showed associations between most likely anticipated reactions to the minimum prices and cessation intentions (tables 4 and 5). Specifically, those with quit intentions were less likely to endorse 'smoke the same amount as I do now' $\left(\mathrm{OR}_{\mathrm{Adj}}=0.48,95 \%\right.$ CI 0.39 to 0.58 , $\mathrm{p}<0.001)$ or 'buy cheaper cigarettes or tobacco online/ abroad' $\left(\mathrm{OR}_{\mathrm{Adj}}=0.56,95 \% \mathrm{CI} 0.36\right.$ to $\left.0.86, \mathrm{p}=0.008\right)$ than those with no quit intentions, but more likely to say they would 'smoke less than I do now' $\left(\mathrm{OR}_{\mathrm{Adj}}=1.94,95 \% \mathrm{CI}\right.$ 1.39 to $2.72, \mathrm{p}<0.001)$ or 'try to quit' $\left(\mathrm{OR}_{\mathrm{Adj}}=10.45,95 \% \mathrm{CI}\right.$ 5.59 to $19.52, \mathrm{p}<0.001)$. Existing use of an e-cigarette (and increased frequency of use) was positively associated with reporting that they would likely 'use e-cigarettes some or all of the time' $(\mathrm{p}<0.001)$, as too was reporting existing quit intentions $\left(\mathrm{OR}_{\mathrm{Adj}}=1.73,95 \%\right.$ CI 1.02 to 2.95 , $\mathrm{p}=0.043$ ).

After controlling for demography and smoking status, the logistic regressions also showed some associations between price sensitivity and most likely reactions to the minimum prices (tables 4 and 5). Specifically, those who had thought about the cost of smoking 'Often' were less likely to endorse 'smoke the same amount as I do now' $\left(\mathrm{OR}_{\mathrm{Adj}}=0.57,95 \%\right.$ CI 0.46 to $\left.0.70, \mathrm{p}<0.001\right)$ or 'buy cheaper cigarettes or tobacco online/abroad' $\left(\mathrm{OR}_{\mathrm{Adj}}=0.50,95 \%\right.$ CI 0.27 to $\left.0.94, \mathrm{p}=0.032\right)$ compared with those thinking about it less often, but more likely to say they would 'try to quit' $\left(\mathrm{OR}_{\mathrm{Adj}}=3.30,95 \mathrm{CI} 2.46\right.$ to 4.43 , $\mathrm{p}<0.001)$.

\section{Impact of hypothetical minimum prices on staying quit}

Almost two-fifths (38.5\%, weighted) of ex-smokers said the minimum prices would help them stay quit 'A lot', while 20.1\% said they would 'Not at all' help. A logistic regression found that believing the minimum prices would help 'A lot' with staying quit was greater among participants from the lower social grades (C2DE) compared with higher (ABC1) grades $\left(\mathrm{OR}_{\mathrm{Adj}}=1.80,95 \% \mathrm{CI} 1.30\right.$ to 2.49 , $\mathrm{p}<0.001$ ) (table 6).

\section{DISCUSSION}

The findings are consistent with suggestions that a minimum retail price may be an effective, non-taxation, mechanism for reducing smoking. ${ }^{27-30}$ Approximately a fifth of cigarette smokers anticipated they would most likely try to reduce smoking or try to quit in response to the minimum prices, while approximately two-fifths of ex-smokers said the minimum prices would help them stay quit. That anticipation of smoking less or trying to quit was more likely among those already reporting quit intentions, and that increased use of e-cigarettes was more likely among those who already reported using these products (and particularly those using them more frequently), suggests that minimum pricing may provide additional encouragement to those already trying to alter their smoking behaviour. 


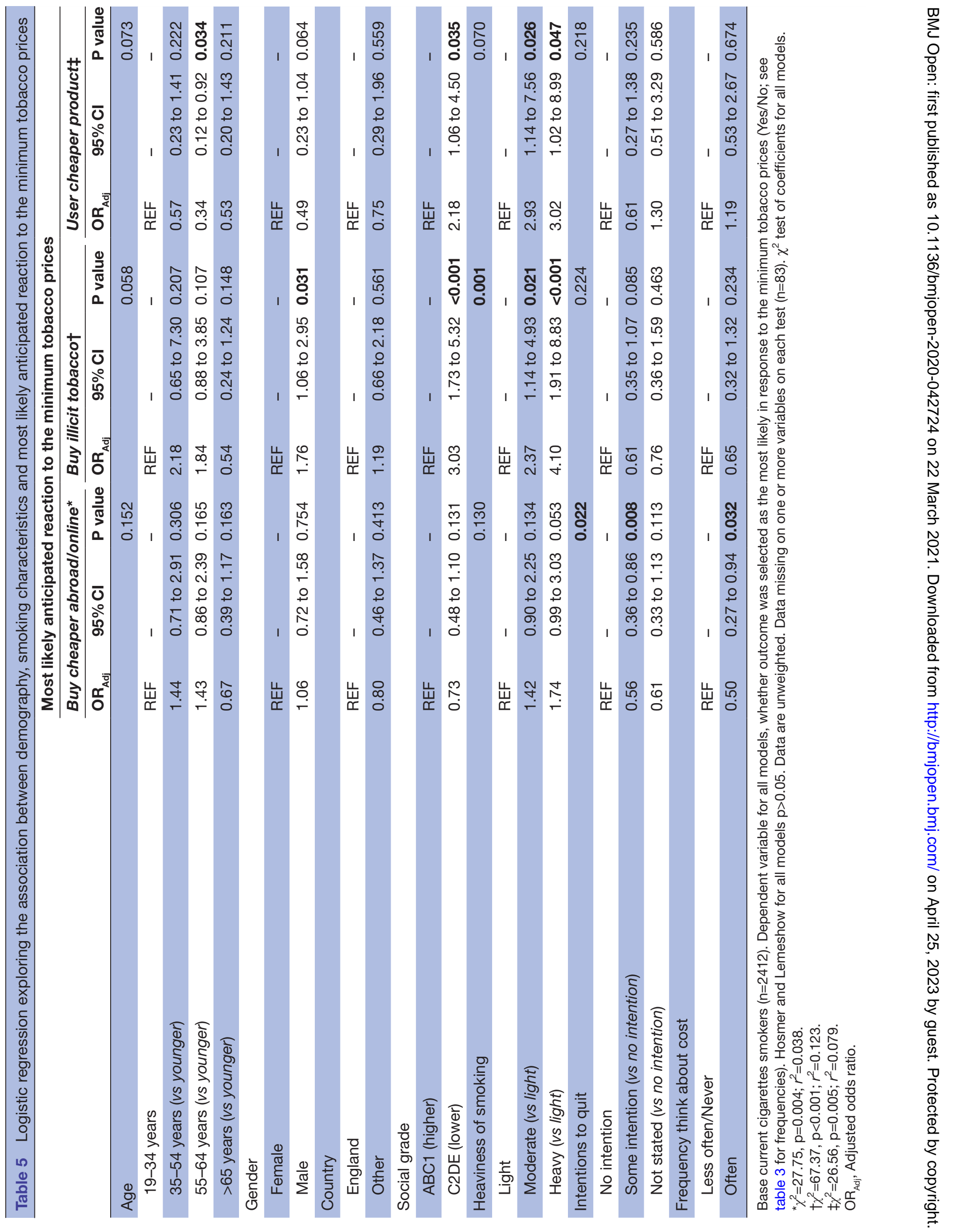


Table 6 Logistic regression exploring the association between demographics, recency of quitting, and agreement the minimum prices would help ex-smokers stay quit 'a lot'

\begin{tabular}{|c|c|c|c|c|}
\hline \multirow[b]{2}{*}{ Variable and reference categories } & \multicolumn{4}{|c|}{ Reporting the hypothetical minimum prices would help stay quit 'A lot' } \\
\hline & $\mathbf{n}$ & $\mathrm{OR}_{\mathrm{Adj}}$ & $95 \% \mathrm{Cl}$ & $\begin{array}{l}P \\
\text { value }\end{array}$ \\
\hline Age & & & & 0.228 \\
\hline 19-34 years & 110 & REF & - & - \\
\hline $35-54$ years (vs younger) & 274 & 1.33 & 0.83 to 2.13 & 0.235 \\
\hline 55-64 years (vs younger) & 119 & 1.49 & 0.96 to 2.30 & 0.074 \\
\hline$>65$ years (vs younger) & 138 & 1.18 & 0.80 to 1.75 & 0.411 \\
\hline \multicolumn{5}{|l|}{ Gender } \\
\hline Female & 332 & REF & - & - \\
\hline Male & 309 & 0.86 & 0.62 to 1.19 & 0.358 \\
\hline \multicolumn{5}{|l|}{ Country } \\
\hline England & 533 & REF & - & - \\
\hline Other & 108 & 1.04 & 0.68 to 1.60 & 0.844 \\
\hline \multicolumn{5}{|l|}{ Social grade } \\
\hline ABC1 (higher) & 384 & REF & - & - \\
\hline C2DE (lower) & 257 & 1.80 & 1.30 to 2.49 & $<0.001$ \\
\hline \multicolumn{5}{|l|}{ When stopped smoking } \\
\hline In the past year & 306 & REF & - & - \\
\hline More than a year ago & 335 & 1.26 & 0.91 to 1.74 & 0.161 \\
\hline
\end{tabular}

Base: Ex-smokers $(n=700)$.

Dependent variable: Whether the minimum price would help the stay quit ( $A$ lot vs Lower Agreement).

Data are unweighted.

Data missing on one or more variables (including saying 'not sure' for whether minimum price would help them stay quit) ( $\mathrm{n}=59$ ).

Hosmer and Lemeshow: $\chi^{2}(8)=7.03, p=0.533$.

$\chi^{2}$ test of coefficients for final model stage: $\chi^{2}(7)=22.11, \mathrm{p}=0.002$; Nagelkerke $R^{2}=0.046$.

Classification accuracy for final model stage: $60.1 \%$.

$\mathrm{OR}_{\text {Adj }}$, Adjusted odds ratio.

The findings suggest that minimum pricing may have a greater impact on price-sensitive consumers. Specifically, smokers from lower social grades were less likely to anticipate maintaining current smoking levels in response to the minimum prices, consistent with suggestions of heightened price sensitivity among this group. ${ }^{4-6}$ Ex-smokers from the lower social grades were also more likely to suggest that the minimum prices would help them stay quit. These findings provide precautionary support to the proposition that minimum pricing could have a more pronounced impact in the most deprived areas and help reduce inequalities, ${ }^{28} 29$ a key priority for governments in the $\mathrm{UK},{ }^{30}$ although further investigation is required, for example through economic modelling (eg, see previous work ${ }^{40}$ ) or using granular indications of disposable income and deprivation. It is also important to consider unintended consequences. We found that a minority of cigarette smokers, particularly heavy smokers and those from lower social grades, indicated they would most likely purchase illicit products or switch to cheaper products (eg, cigarillos) in response to minimum prices, both of which may confound any positive impact on inequalities.
A minimum retail price is a viable tobacco control option for the UK. After a protracted contest about legality and proportionality, ${ }^{41}$ Scotland recently implemented minimum pricing for alcohol, set at $£ 0.50$ per unit (ie, per $10 \mathrm{ml}$ of pure alcohol), ${ }^{42}$ with the policy introduced on top of UK-wide taxation measures. Minimum unit pricing for alcohol is now also law in Wales ${ }^{43}$ and is scheduled for implementation in the Ireland, ${ }^{44}$ which provides evidence of reproducibility. While the Scottish Government could introduce minimum pricing for tobacco, a UK-wide policy would eliminate the risk of cross-border sales between Scotland and England. To inform implementation, it is also important to evaluate how a minimum retail price (or the level set) would interact with existing UK-wide taxation, ideally using longitudinal retail data. For example, eventually the price-per-cigarette set under the MET would exceed the minimum retail price due to the escalator, although the MET does not make retailing at this threshold a legal requirement.

\section{Limitations and future directions}

The minimum prices were based on the cheapest products in supermarkets during survey development and 
may not reflect prices in smaller retailers who account for a substantial proportion of tobacco sales in the UK. ${ }^{45}$ Data were also not available to assess what proportion of cigarette sales in the UK would have been below the minimum prices used, although our values exceed the average price-per-cigarette/gram reported in recent UK market data, particularly the subvalue, value and mid-price categories. ${ }^{45}{ }^{46}$ Future data examining how the proportion of smokers who anticipate trying to quit increases in relation to different price thresholds would also be beneficial, as too would research that controls for an objective measure of typical or last price paid (eg, using consumer panel data or retail receipts to segment by price-per-cigarette or gram). For example, research could also ask participants to indicate the highest price they would be willing to pay, ${ }^{20}$ and assess how reactions vary at increments leading up to, and exceeding, these values. While social grade was included as a covariate, future research using granular measurements of disposable income, employment status and area deprivation would also provide necessary insight into how the impact of minimum pricing varies among lower income or more deprived groups. Moreover, our analyses only examined reactions among cigarette and roll-your-own tobacco users combined. As UK Government data suggest that illicit market share is greater for roll-your-own than cigarettes ${ }^{47}$ further research examining how anticipated reactions vary among dual users versus exclusive users of roll-your-own or cigarettes would be of value. Put simply, while the current data suggest some utility of minimum tobacco pricing, these are only preliminary steps in understanding the potential impact in the UK. Further examination remains a requirement.

The data are cross-sectional and cannot demonstrate causality. For example, anticipating purchase of illicit tobacco could be a reflection of existing behaviour, a valid hypothesis given that anticipation of increased e-cigarette use was associated with pre-existing uptake. Our data also only relate to UK consumers and the UK market, and come from a non-probability market research panel. Other countries have different pricing and taxation structures, tobacco control policies ${ }^{48}$ and different geographical contexts compared with the UK (eg, land borders which may facilitate easier cross-border purchasing). Further research is needed to understand the generalisability of these findings to other jurisdictions. Furthermore, the questions on minimum pricing were only included in the third ATPS wave and we cannot know how the findings would have differed if based on all participants recruited in the first wave (ie, whether certain subpopulations are more likely to be lost to attrition) and cannot know if anticipated reactions have varied over time or as other tobacco control policies were implemented (eg, MET). Finally, the data are based on self-reported anticipated reactions to minimum prices, and responses may be influenced by social desirability, response bias and recall errors. Future research employing discrete choice experimental designs would be beneficial.

\section{CONCLUSION}

In response to hypothetical minimum prices for cigarettes and roll-your-own tobacco, approximately a fifth of smokers in the UK indicated that they would smoke less or try to quit and almost two-fifths of ex-smokers that they would stay quit. Only a minority suggested they would purchase illicit tobacco. Minimum pricing may help reduce health inequalities given that smokers and ex-smokers from lower social grades were more likely to anticipate that the minimum prices may help them reduce consumption or stay quit. Minimum pricing may also provide an additional stimulus to those already trying to alter their smoking behaviour by increasing quit attempts or use of e-cigarettes. These are, however, only preliminary findings in relation to the potential efficacy of this policy in the UK. Future research should consider how consumers respond to different minimum price thresholds, examine the impact of base price sensitivity (eg, how reactions vary among those purchasing in the cheaper price segments versus more expensive segments), explore how reactions interact with other factors (eg, disposable income) and use discrete experiments of consumer behaviour.

\section{Twitter Nathan Critchlow @n_critchlow and Catherine Best @cathbest}

Acknowledgements The authors pay thanks to Professor Ann McNeil and Dr Sara Hitchman, King's College London, for their involvement in wave one and wave two of the ATPS. The authors also thank YouGov for their support in conducting the fieldwork at all three waves. We also acknowledge Cancer Research UK and the British Heart Foundation, who funded wave one and wave two of the ATPS.

Contributors Conceptualisation: NC, CM. Data curation: NC, CB. Formal analysis: NC. Funding acquisition: CM, MS. Investigation: NC, CM, CB, MS. Methodology: CM, NC, CB, MS. Project administration: CM, MS. Supervision: CM, MS. Writing, original draft: NC, CM. Writing, reviewing and editing: NC, CM, CB, MS.

Funding The third wave of the Adult Tobacco Policy Survey (ATPS) was funded by the Department of Health and Social Care (DHSC) through the Public Health Policy Research Unit (PH-PRU) (Stirling Funding ID: 1080109). The views expressed as those of the authors, and do not represent those of their respective funder(s)/ employer(s).

\section{Competing interests None declared.}

Patient and public involvement Patients and/or the public were not involved in the design, or conduct, or reporting or dissemination plans of this research.

Patient consent for publication Not required.

Provenance and peer review Not commissioned; externally peer reviewed.

Data availability statement Data are available upon reasonable request. Data are available upon reasonable request from the researchers.

Open access This is an open access article distributed in accordance with the Creative Commons Attribution Non Commercial (CC BY-NC 4.0) license, which permits others to distribute, remix, adapt, build upon this work non-commercially, and license their derivative works on different terms, provided the original work is properly cited, appropriate credit is given, any changes made indicated, and the use is non-commercial. See: http://creativecommons.org/licenses/by-nc/4.0/.

ORCID iDs

Nathan Critchlow http://orcid.org/0000-0001-9145-8874

Catherine Best http://orcid.org/0000-0002-3652-2498

\section{REFERENCES}

1 Dewhirst T. Price and tobacco marketing strategy: lessons from 'dark' markets and implications for the WHO Framework Convention on Tobacco Control. Tob Control 2012;21:519-23. 
2 Chaloupka FJ, Cummings KM, Morley CP, et al. Tax, price and cigarette smoking: evidence from the tobacco documents and implications for tobacco company marketing strategies. Tob Control 2002;11 Suppl 1:i62-72.

3 Rothwell L, Britton J, Bogdanovica I. The relation between cigarette price and hand-rolling tobacco consumption in the UK: an ecologica study. BMJ Open 2015;5:e0077697.

4 Hyland A, Bauer JE, Li Q, et al. Higher cigarette prices influence cigarette purchase patterns. Tob Control 2005;14:86-92.

5 Nikaj S, Chaloupka FJ. The effect of prices on cigarette use among Youths in the global youth tobacco survey. Nicotine Tob Res 2014;16 Suppl 1:S16-23.

6 Gilmore AB, Tavakoly B, Hiscock R, et al. Smoking patterns in Great Britain: the rise of cheap cigarette brands and roll your own (RYO) tobacco. J Public Health 2015;37:78-88.

7 Chaloupka FJ, Yurekli A, Fong GT. Tobacco taxes as a tobacco control strategy. Tob Control 2012;21:172-80.

8 Chaloupka FJ, Straif K, Leon ME, et al. Effectiveness of Tax and price policies in tobacco control. Tob Control 2011;20:235-8.

9 Yeh C-Y, Schafferer C, Lee J-M, et al. The effects of a rise in cigarette price on cigarette consumption, tobacco taxation revenues, and of smoking-related deaths in $28 \mathrm{EU}$ countries-- applying threshold regression modelling. BMC Public Health 2017;17:676.

10 World Health Organisation [WHO]. Tobacco free initiative (TFI), 2020. Available: https://www.who.int/tobacco/economics/taxation/en/

11 HM Revenue and Customs. Tobacco product duty rates, 2020. Available: https://www.gov.uk/government/publications/rates-andallowances-excise-duty-tobacco-duty/excise-duty-tobacco-dutyrates

12 Tobacco Manufacturers Association. Tobacco taxation in the UK, 2017. Available: http://www.the-tma.org.uk/wp-content/uploads/ 2017/02/TMA-Taxation_Briefing_final.pdf

13 HM Revenue and Customs. Policy paper: tobacco products duty rates autumn 2020, 2020. Available: https://www.gov.uk/government/ publications/tobacco-duty-rates-autumn-2020/tobacco-duty-ratesautumn-2020

14 HM Revenue and Customs. Policy paper: minimum excise tax for cigarettes, 2017. Available: https://www.gov.uk/government/ publications/minimum-excise-tax-for-cigarettes/minimum-excisetax-for-cigarettes

15 Department of Health. Tobacco packaging guidance: guidance for retailers, manufacturers and distributors of tobacco products, enforcement agencies and the public on changes to tobacco packaging from 20 may 2016. London: Department of Health, 2017.

16 Breton MO, Britton J, Huang Y, et al. Cigarette brand diversity and price changes during the implementation of plain packaging in the United Kingdom. Addiction 2018;113:1883-94.

17 Robinson M, Reid G. Population cigarette consumption in Great Britain: novel insights using retail sales data. BMC Public Health 2017; $17: 941$.

18 Ross H, Blecher E, Yan L, et al. Do cigarette prices motivate smokers to quit? new evidence from the ITC survey. Addiction 2011;106:609-19.

19 Park E-J, Park S, Cho S-i, et al. What cigarette price is required for smokers to attempt to quit smoking? findings from the ITC Korea waves 2 and 3 survey. Tob Control 2015;24:iii48-55.

20 Ross H, Blecher E, Yan L, et al. Predictors of what smokers say they will do in response to future price increases. findings from the International tobacco control (ITC) four country survey. Nicotine Tob Res 2011;13:419-25.

21 Scollo M, Hayes L, Wakefield M. What price quitting? the price of cigarettes at which smokers say they would seriously consider trying to quit. BMC Public Health 2013;13:650.

22 Hiscock R, Branston JR, McNeill A, et al. Tobacco industry strategies undermine government Tax policy: evidence from commercial data. Tob Control 2017;27:488-97.

23 Hiscock R, Branston JR, Partos TR, et al. Uk tobacco price increases: driven by industry or public health? Tob Control 2019;28:e148-50.

24 van Schalkwyk MCl, McKee M, Been JV, et al. Analysis of tobacco industry pricing strategies in 23 European Union countries using commercial pricing data. Tob Control 2019;28:e102-9.

25 Gilmore AB, Tavakoly B, Taylor G, et al. Understanding tobacco industry pricing strategy and whether it undermines tobacco Tax policy: the example of the UK cigarette market. Addiction 2013;108:1317-26.

26 Partos TR, Hiscock R, Gilmore AB. Impact of tobacco Tax increases and industry pricing on smoking behaviour and inequalities: a mixed methods study. Southampton: NIHR Journals Library, 2020.
27 Golden SD, Smith MH, Feighery EC, et al. Beyond excise taxes: a systematic review of literature on non-tax policy approaches to raising tobacco product prices. Tob Control 2016;25:377-85.

28 Whitehead R, Brown L, Riches E. Rapid evidence review: strengths and limitations of tobacco taxation and pricing strategies. Edinburgh: NHS Health Scotland, 2018.

29 Shortt NK, Tunstall H, Mitchell R, et al. Using point-of-sale data to examine tobacco pricing across neighbourhoods in Scotland. Tob Control 2021;30:168-76.

30 Moodie C, Angus K, Stead M. A systematic review of research exploring the response of consumers, retailers and tobacco companies to standardised packaging in the United Kingdom. Stirling: Institute for Social Marketing, 2019.

31 Moodie C, Brose LS, Lee HS, et al. How did smokers respond to standardised cigarette packaging with new, larger health warnings in the United Kingdom during the transition period? A cross-sectional online survey. Addict Res Theory 2020;28:53-61.

32 Heatherton TF, Kozlowski LT, Frecker RC, et al. Measuring the heaviness of smoking: using self-reported time to the first cigarette of the day and number of cigarettes smoked per day. $\mathrm{Br} J$ Addict 1989;84:791-800.

33 Borland $\mathrm{R}$, Yong $\mathrm{H}-\mathrm{H}, \mathrm{O}^{\prime}$ Connor RJ, et al. The reliability and predictive validity of the Heaviness of smoking index and its two components: findings from the International tobacco control four country study. Nicotine Tob Res 2010;12 Suppl:S45-50.

34 Aleyan S, Driezen P, McNeill A, et al. Evaluating the impact of introducing standardized packaging with larger health-warning labels in England: findings from adult smokers within the EUREST-PLUS ITC Europe surveys. Eur J Public Health 2020;30:iii91-7.

35 Simonavicius E, McNeill A, Cheeseman $\mathrm{H}$, et al. Smokers who have not tried alternative nicotine products: a 2019 survey of adults in Great Britain. Harm Reduct J 2020;17:46.

36 Borland $\mathrm{R}$, Yong $\mathrm{H}-\mathrm{H}$, Balmford J, et al. Motivational factors predict quit attempts but not maintenance of smoking cessation: findings from the International tobacco control four country project. Nicotine Tob Res 2010;12:S4-11.

37 Cooper J, Borland R, Yong $\mathrm{H}-\mathrm{H}$, et al. To what extent do smokers make spontaneous quit attempts and what are the implications for smoking cessation maintenance? findings from the International tobacco control four country survey. Nicotine Tob Res 2010;12 Suppl:S51-7.

38 Moodie C, Angus K, Mitchell D, et al. How tobacco companies in the United Kingdom prepared for, and responded to, standardised packaging of cigarettes and rolling tobacco. Tob Control 2018;27:e85-92.

39 Kantar. Grocery market share (12 weeks ending), 2020. Available: https://www.kantarworldpanel.com/en/grocery-market-share/greatbritain

40 Holmes J, Meng Y, Meier PS, et al. Effects of minimum unit pricing for alcohol on different income and socioeconomic groups: a modelling study. Lancet 2014;383:1655-64.

41 Holmes J, Meier PS, Angus C, et al. Scotland's policy on minimum unit pricing for alcohol: the legal barriers are gone, so what are the implications for implementation and evaluation? Addiction 2018;113:203-4.

42 Beeston C, Robinson M, Giles L, et al. Evaluation of minimum unit pricing of alcohol: a mixed method natural experiment in Scotland. Int J Environ Res Public Health 2020;17:e3394.

43 Welsh Government. Guidance on the implementation of minimum unit pricing for alcohol in Wales. Cardiff, Wales: Welsh Government, 2020.

44 O'Dwyer C. Public health (alcohol) act. DrugsNet Ireland 2019;71:6-8.

45 Critchlow N, Stead M, Moodie C, et al. Pricing of tobacco products during, and after, the introduction of standardized packaging: an observational study of retail price data from independent and convenience (small) retailers in the United Kingdom. Addiction 2019;114:523-33.

46 Hiscock R, Augustin NH, Branston JR, et al. Standardised packaging, minimum excise tax, and RYO focussed Tax rise implications for UK tobacco pricing. PLoS One 2020;15:e0228069.

47 HM Revenue \& Customs. Measuring Tax gaps 2020 edition: Tax gap estimates for 2018 to 2019. London, UK: HM Revenue \& Customs, 2020.

48 Joossen L, Feliu FE. The Tobacco Control Scale 2019 in Europe. Brussels, Belgium: Association of European Cancer Leagues and Catalan Institute of Oncology, 2020. 